\title{
The Hippo Pathway in Innate Anti-microbial Immunity and Anti-tumor Immunity
}

\author{
Qian Zhang ${ }^{1,2}$, Ruyuan Zhou ${ }^{1}$ and Pinglong $X u^{1,2 *}$ \\ ${ }^{1}$ MOE Laboratory of Biosystems Homeostasis \& Protection and Innovation Center for Cell Signaling Network, Life Sciences \\ Institute, Zhejiang University, Hangzhou, China, ${ }^{2}$ Zhejiang Provincial Key Laboratory of Pancreatic Disease, Department of \\ Hepatobiliary and Pancreatic Surgery, The First Affiliated Hospital, Zhejiang University School of Medicine, Hangzhou, China
}

OPEN ACCESS

Edited by:

Lanfen Chen,

Xiamen University, China

Reviewed by:

Kang Wei,

The Chinese University of

Hong Kong, China

Hyun Woo Park,

Yonsei University, South Korea

*Correspondence:

Pinglong $X u$

xup/@zju.edu.cn

Specialty section:

This article was submitted to

Molecular Innate Immunity,

a section of the journal

Frontiers in Immunology

Received: 10 January 2020

Accepted: 05 June 2020

Published: 04 August 2020

Citation:

Zhang Q, Zhou R and Xu P (2020) The

Hippo Pathway in Innate

Anti-microbial Immunity and

Anti-tumor Immunity.

Front. Immunol. 11:1473.

do: 10.3389/fimmu.2020.01473
The Hippo pathway responds to diverse environmental cues and plays key roles in cell fate determination, tissue homeostasis, and organ regeneration. Aberrant Hippo signaling, on the other hand, has frequently been implicated in diversified pathologies such as cancer and immune dysfunction. Here, we summarize the recent but rapid progress in understanding the involvement of the Hippo pathway in innate immunity, with a special focus on the intrinsic mechanisms and mutual interactions between Hippo-YAP signaling and the innate immune response and its physiological impacts on anti-microbial immunity and anti-tumor immunity. Moving forward, we believe that systematic investigations under the physiological setting are needed to draw a clearer picture of the actions of Hippo in innate immunity.

Keywords: Hippo-YAP signaling, innate immunity, anti-tumor immunity, anti-microbial, nucleic acid sensing, antiviral immunity, interferon, cGAS-STING

\section{INTRODUCTION}

The Hippo pathway responds to diverse extracellular cues and plays key roles in tissue homeostasis, organ regeneration, and tumorigenesis. Originally discovered in Drosophila, the Hippo pathway is highly conserved in evolution (1-4). A kinase cascade by four tumor suppressors constitutes the core of the Hippo pathway, comprising two signaling complexes-the Hpo-Sav (MST-SAV in mammals) and the Wts-Mat (LATS-MOB in mammals), which govern the cellular localization, activity, and fate of signaling effectors YAP and TAZ $(1,5-8)$. Transcription coactivators YAP and TAZ therefore serve as downstream effectors in response to unfavorable growth conditions such as those derived from mechanical signals, cell adhesion, GPCR ligands, and cellular stresses and instructed by upstream kinases including MST, MAP4Ks, TAO, and AMPK (9-19). Activated LATS1/2 kinases directly phosphorylate five conserved serine residues on YAP (20), which drives the binding of YAP to 14-3-3 proteins for sequestration and cytoplasmic retention $(21,22)$ as well as the ubiquitination and proteasomal degradation $(20,23,24)$. Otherwise, YAP/TAZ are localized in the nucleus to form transcription complex and activate the TEAD family transcription factors $(25,26)$, thereby transcribing target genes to promote cell proliferation, survival, and migration (27).

In Drosophila, mutations in major kinases of the Hippo pathway (Hpo/Wts) or their upstream regulators (Ex, Mer, Kibra, Ft, etc.) lead to overgrowth of eyes, wings, and other organs, mainly due to a sustained Yki activation that induces excessive cell proliferation $(23,28)$. Correspondingly, a sustained activation of YAP in mouse livers leads to cell transformation and tumor formation (22), while knocking out of YAP in mouse tissues results in various abnormalities in heart, skin, and 
kidney (29-32). YAP and TAZ are also highly active in stem cells and ancestral cells of various tissues and play important roles in the maintenance of stemness (33). TAZ is also involved in maintaining the self-renewal of breast cancer stem cells (34), while YAP causes genomic instability in medulloblastoma (35). Taken together, these observations indicate that the activities of YAP/TAZ resulting from Hippo signaling are key factors in cell fate determination and tissue homeostasis.

\section{SIGNALING REGULATION AND CROSSTALKS OF THE HIPPO PATHWAY}

Since its discovery, the physiological and pathological aspects of the Hippo pathway have been steadily established, particularly in development, homeostasis, and regeneration of organs, including liver, heart, intestine, brain and central nervous system (CNS), lung, and kidney (36), and in diseases of cancer, immune disorder, and cardiovascular dysfunction (27). The regulation of Hippo-YAP signaling appears to be very complicated (Figure 1), and there are crosstalks with the Notch pathway (37), the TGF$\beta$ pathway (38), the WNT pathway (39), G protein-coupled receptor (GPCR) signaling $(11,40)$, and innate immune signaling $(41,42)$. Recently, two studies have revealed that the MAP4K kinase family, including MAP4K1/2/3/5 and MAP4K4/6/7, directly phosphorylate and activate LATS1/2 independent of MST1/2 (13, 14), indicating the existence of other kinases involved in LATS1/2 regulation under the distinct tissue and signaling niches. Moreover, YAP and TAZ are targeted by many other kinases such as AMPK (17, 18), CDK1 (20), JNK (43), HIPK (44), and the tyrosine kinases c-Abl (45) and the Src family (46-49), indicating that YAP and TAZ possess a variety of additional regulations independent of the Hippo pathway. One of the major research focuses regarding the Hippo pathway is on understanding how it integrates with cellular intrinsic factors and cooperates with the other signaling pathways to regulate a myriad of physiological and pathological processes. In this review, we are focusing our discussions of the Hippo-YAP pathway on a specific topic, innate immunity.

\section{THE FUNCTION OF THE HIPPO PATHWAY IN INNATE IMMUNE CELLS}

By regulating the transactivation of TEAD family transcription factors, Hippo-YAP signaling exerts critical roles in cell proliferation, apoptosis, migration, and pluripotency (50). Recently, accumulating evidence has suggested that the Hippo pathway is considerably involved in regulation of the differentiation, metabolism, and functions of innate immune cells (51-56). Macrophages and dendritic cells (DCs) are pivotal types of innate immune cells connecting the innate and adaptive immunity (57-59). Under physiological conditions, macrophages are polarized into M1 type, which mainly engages in pro-inflammatory and anti-tumor responses, or differentiated into the M2 type, which is mainly responsible for anti-inflammatory and pro-tumorigenic signals $(60,61)$.
Activated YAP/TAZ in tumor cells and hepatocyte appears to be an effective attractant to drive the tissue infiltration of macrophages in the contexts of the tumor immune-environment and organ fibrosis, although the expression levels of YAP/TAZ in macrophages are still a controversial topic (62). For example, the activation of YAP in hepatocellular carcinoma underlies the M2 macrophage recruitment by tumor-initiating cells (TICs) (63) or promotes the migration and infiltration of M1-like macrophages (53), while the genetic deletion of Mst1/2 in hepatocytes upregulates MCP1 expression and causes a massive infiltration of macrophages with mixed M1 and M2 phenotypes, which promotes the development of HCC (64). A recent report also showed that YAP in macrophages impaired the IL-4/IL-13induced M2 macrophage polarization but meanwhile promoted the LPS/ IFN- $\gamma$-triggered activation of M1 macrophage, which produced excessive IL- 6 to aggravate intestinal bowel disease (IBD) (65). In another report, CYR61, but not CCL2/CSF1 (63), functioned as the downstream factor of YAP/TAZ in hepatocytes to attract liver macrophage infiltration, leading to liver inflammation and fibrosis (66). These intriguing observations may reflect context- and cellular type-dependency of the Hippo pathway in the regulation of macrophage polarization and tissue infiltration.

On the other hand, less is known about the role of the Hippo pathway in DCs, another major group of antigen-presenting cells (APCs) that present antigens to $\mathrm{CD}^{+} \mathrm{T}$ cells and activate cytotoxic $\mathrm{T}$ cells to obliterate virus, bacteria, and tumor cells (67-69). Recently, the Chi group found that the DC-specific deletion of MST1/2, but not LATS kinases or YAP/TAZ, leads to selective disruption of the homeostasis and function of CD $8 \alpha^{+} \mathrm{T}$ cells (51). They revealed that CD $8 \alpha^{+}$DCs exhibited a particularly robust oxidative metabolism that critically relies on MST1/2 signaling to maintain both the bioenergetic activities and mitochondrial dynamics. As a result, MST1/2-deficient CD $8 \alpha^{+}$ DCs were impeded in the presentation of extracellular proteins and cognate peptides to prime $\mathrm{CD}^{+} \mathrm{T}$ cells (51). This report unveils the intriguing interaction between immune signaling and metabolic reprogramming that underlies the unique function of a subset of DCs. In addition, Torres-Bacete and colleagues revealed that depending on CCR7-RhoA signaling, MST1 selectively regulated the cyto-architecture, endocytosis, and migratory speed of mature dendritic cells (mDCs) (55). Taken together, these studies suggest that the Hippo pathway may participate in the homeostasis and function of DCs via distinct mechanisms. The functions of the Hippo pathway in innate immune cells are usually independent of LATS kinases and YAP/TAZ effectors, due to the general deficiency of YAP and TAZ expression in these cells.

\section{THE HIPPO PATHWAY IN REGULATION OF INNATE IMMUNE SIGNALING}

Innate immunity, which presents in both immune cells and non-immune cells, functions as the first defense line of defense against pathogen invasion. The host recognizes the pathogenassociated molecular patterns (PAMPs) of pathogens, and this 


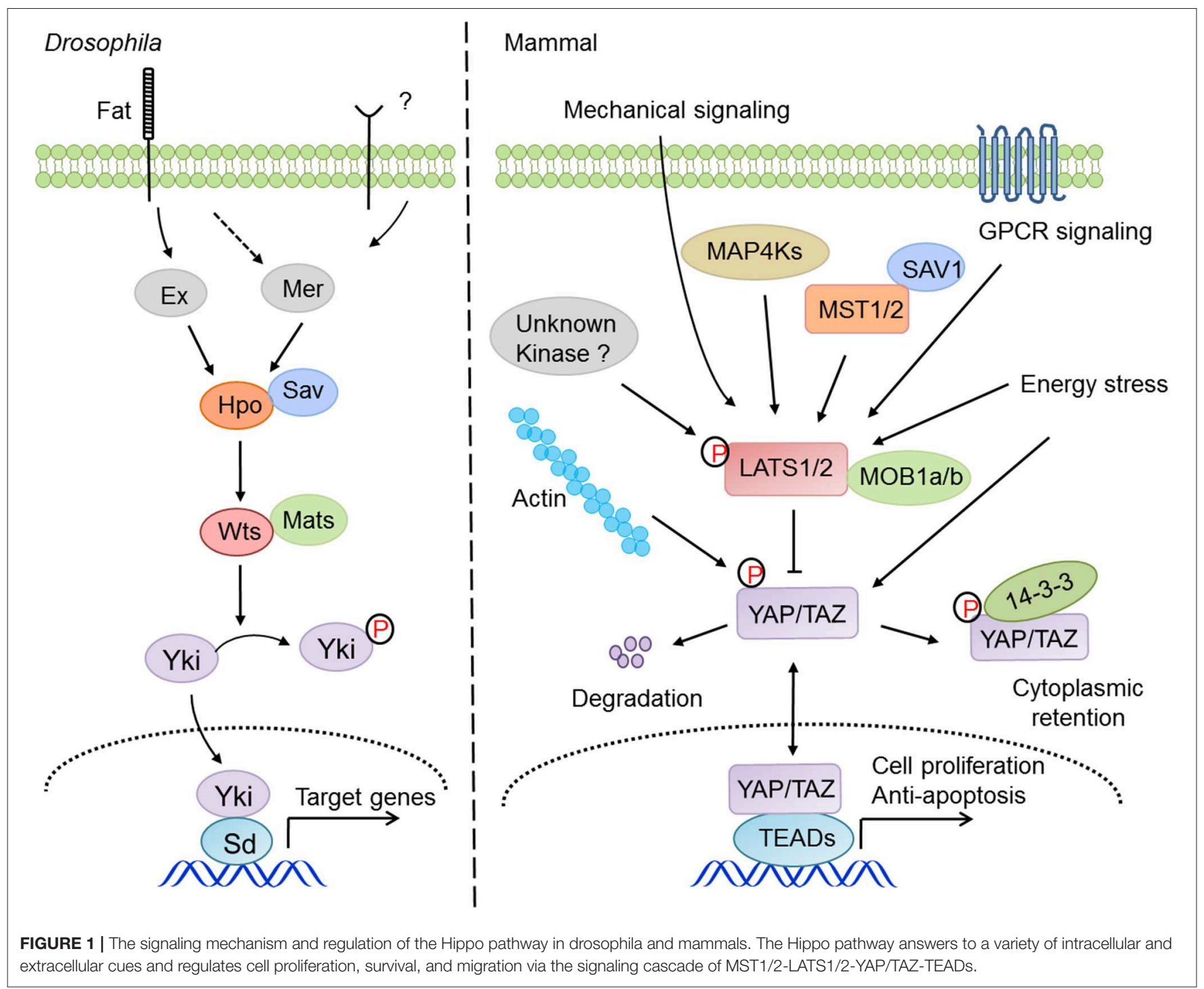

triggers immune responses via numerous pattern recognition receptors (PRRs) (70), including membrane-anchored Toll-like receptors (TLRs) and C-type lectin receptors (CLRs) (71, 72), which are distributed mainly in immune cells, and cytosolic receptors such as RIG-I-like receptors (RLRs) (73-76), Cyclic GMP-AMP synthase (cGAS) (77-80), NOD-like receptors (81, $82)$, and AIM2-like receptors $(83,84)$, which have widespread expression. The Hippo pathway appears considerably involved in the regulation of innate immunity during pathogen infection, which is largely distinct from its canonical roles in organ growth control and tissue homeostasis maintenance. Our group and others have revealed that YAP and TAZ functioned as potent suppressors to compromise the production and signaling of type I interferons (IFN-Is) $(41,85,86)$ and the activation of NF- $\kappa \mathrm{B}$ (42) and that they served as positive regulators for differentiation of the Treg lymphocytes (87). For example, Zhang et al. revealed that YAP and TAZ acted as potent suppressors of TBK1, the central kinase in innate nucleic acid-sensing signaling (33); Deng et al. revealed that YAP/TAZ attenuated NF- $\mathrm{B}$ signaling by directly inhibiting IKK $\alpha / \beta$ activation in an osteoarthritis murine model (88); $\mathrm{Ni}$ et al. found that YAP was highly expressed in Treg cells to amplify TGF $\beta$-SMAD activation, which strengthened Foxp3 expression and Treg functions (87). These observations are supported by the greater severity of inflammatory phenotypes and the elevated anti-tumor immunity in mice with YAP and/or TAZ deficiency (87-92). Studies from several independent groups also suggested that YAP activation facilitated the expression of SOCS3 and suppressed the JAK-STAT inflammatory cascade in astrocytes (89), and during vascular inflammation, prevented NF- $\kappa$ B signaling by associating with TRAF6 and facilitating its degradation (90). In the case of myocardial fibrosis, YAP in epicardium promoted the recruitment of suppressive immune cells Tregs and thus suppressed the post-infarct inflammatory response and myocardial fibrosis (91). These observations under various physiological or pathological conditions thus suggest 


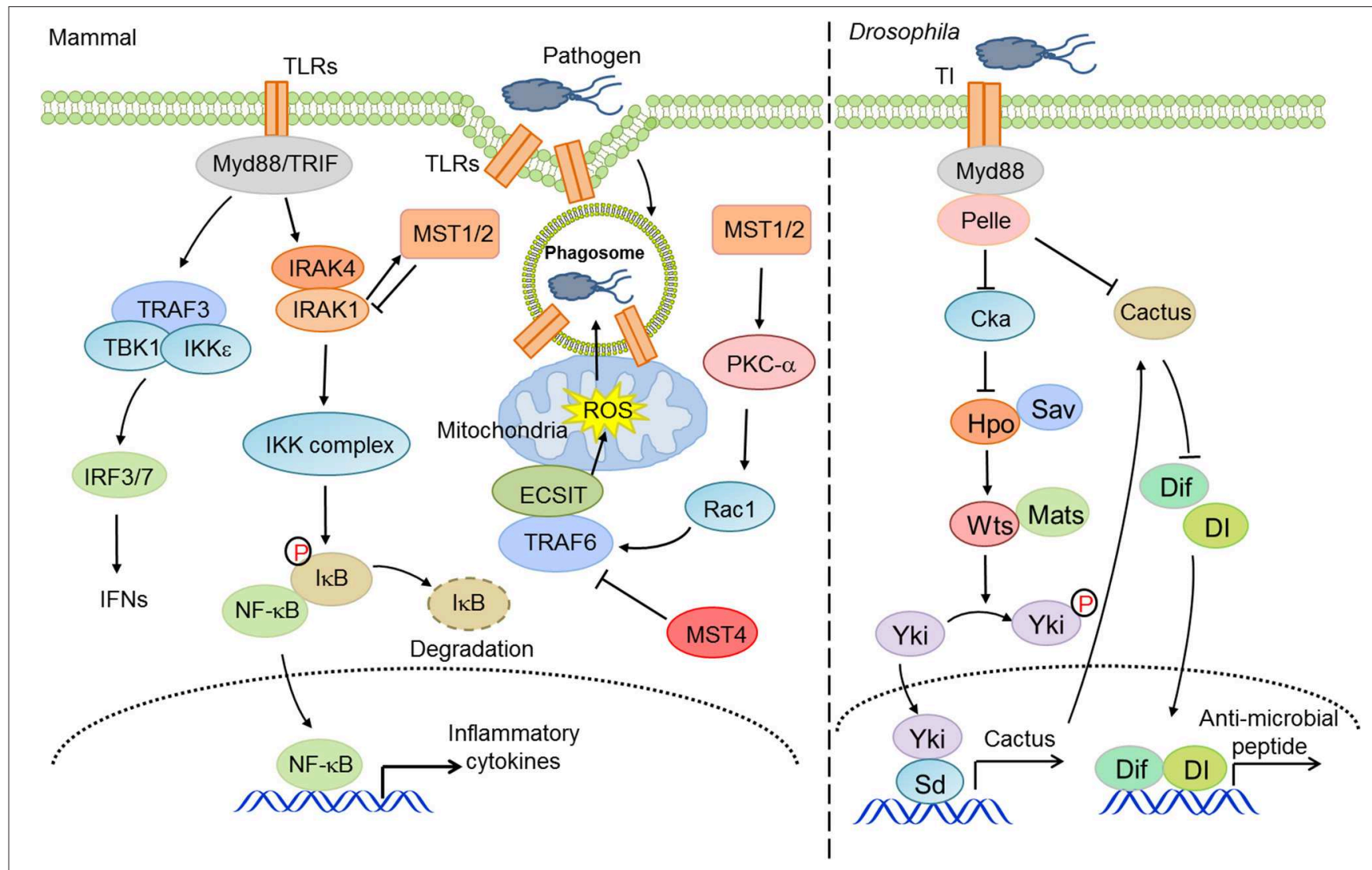

FIGURE 2 | The Hippo pathway in innate anti-bacterial immunity. Hippo-YAP signaling is considerably involved in innate anti-bacterial immunity at multiple layers to address the activity of TLRs and NF-кB and ROS production.

that YAP and TAZ function as suppressors of innate immune signaling and inflammatory responses.

On the other hand, the Guan group reported that deletion of kinases LATS1/2, which resulted in YAP/TAZ activation, induced the secretion of nucleic acid-rich extracellular vesicles (EVs) to promote IFN-I production, dendritic cell maturation, and $\mathrm{CD}^{+} \mathrm{T}$-cell expansion and eventually contributed to antitumor immunity (93). YAP was also shown to promote NF-кB signaling by suppressing USP31, a negative regulator of NF- $\kappa$ B signaling, which resulted in the acceleration of sarcomagenesis (94). In endothelial cells, the activity of YAP/TAZ was suppressed by atheroprotective unidirectional shear stress, which resulted in downregulated expression of pro-inflammatory genes and decreased monocyte infiltration (95). Therefore, the roles of YAP/TAZ in innate immune signaling and inflammation appear to be highly context-dependent.

\section{THE HIPPO PATHWAY IN INNATE ANTI-BACTERIAL IMMUNITY}

Organisms from drosophila to mammals are widely armed with TLR-mediated anti-microbial responses. The Pan group found that silencing of the Hippo pathway or activation of Yorkie in drosophila fat bodies led to an increase in cactus expression, which suppressed NF-кB signaling and thereby decreased the production of anti-microbial peptides, eventually compromising the resistance of host to gram-positive bacteria (42). Upon bacterial infection, the Hippo pathway in Drosophila enterocytes was coupled with the TGF- $\beta$ and Src-MAPK pathways to upregulate the transcription of upd3, which contributed to intestinal stem cell-dependent tissue repair (96). In contrast, LegK7, the effector kinase of L. pneumophila, could mimic the host MST1 kinase to trigger the degradation of YAP/TAZ, which interfered with PPAR $\gamma$ activity and altered the transcriptional profile to impair macrophage anti-bacterial immunity (97). Therefore, the precise mechanisms and physiological roles of Hippo-YAP signaling in innate anti-bacterial immunity may await further investigation.

On the other hand, several studies have unveiled that other core components of the Hippo pathway, independent of the canonical effectors YAP/TAZ, engage in the regulation of innate anti-bacterial immunity. For instance, MST1/2 kinases promoted mitochondria trafficking and reactive oxygen species (ROS) production in phagocytes (98), which facilitated antibacterial responses and bactericidal activity (99). Mechanistically, MST1/2 facilitated the formation of TLR-triggered TRAF6ECSIT complex, which recruited mitochondria to phagosomes and accelerated the production of mitochondrial ROS (98). Intriguingly, MST1 disrupted the secretion of TLR4/9-triggered 


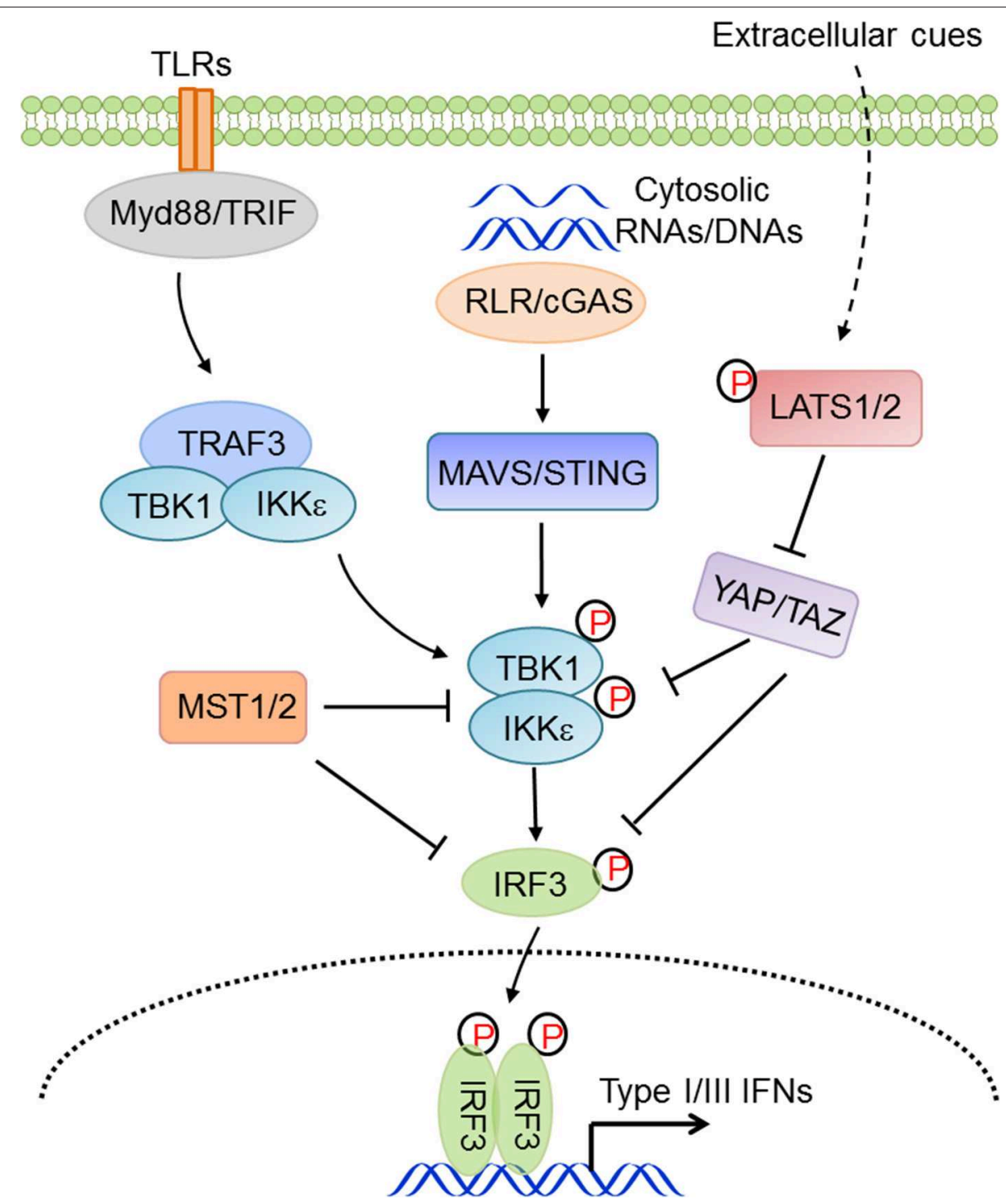

FIGURE 3 | The Hippo pathway in innate antiviral immunity. Hippo-YAP signaling connects the extracellular cues to innate antiviral responses via complex regulations at multiple levels and in distinct physiological contexts.

inflammatory cytokines to avoid chronic inflammation in hepatocellular carcinomas (HCCs) via priming the degradation of IRAK1 in macrophages (100). MST4, a homologous kinase of MST1/2, also restricted inflammatory responses via the phosphorylation of TRAF6 (101). Taken together, these studies suggest an important but complicated role for the Hippo pathway, canonical or non-canonical, in innate anti-bacterial immunity (Figure 2).

\section{THE HIPPO-YAP PATHWAY IN INNATE ANTIVIRAL IMMUNITY}

In vertebrates, cytoplasmic nucleic acid sensing, which monitors both foreign and aberrant nucleic acids in the cytosol, is an essential component of innate antiviral immunity. RIG-Ilike receptors (RLRs, including RIG-I and MDA5) surveil for heterogonous or aberrant RNA molecules (73-76), while abnormal nuclear or mitochondrial DNA molecules are primarily sensed by cGAS (77-80), which initiates cGAS-STING signaling, or by Aim2, which initiates the inflammasomal program. Facilitated by mitochondrial or endoplasmic reticulum-localized adaptor proteins MAVS/VISA/IPS-1/Cardif (102-104) or STING/MITA/ERIS (105, 106), nucleic acid sensing activates TBK1 and $\mathrm{IKK} \varepsilon$, which are responsible for phosphorylation and mobilization of IRF3. Activated IRF3 is then dimerized and translocated into the nucleus where it functions as a transcriptional factor by synergizing with NF- $\mathrm{B}$ to transcribe type I IFNs and ISGs, eventually establishing an appropriate immune state and modulating the adaptive immunity $(107,108)$. Our group found that YAP and TAZ functioned as intrinsic 


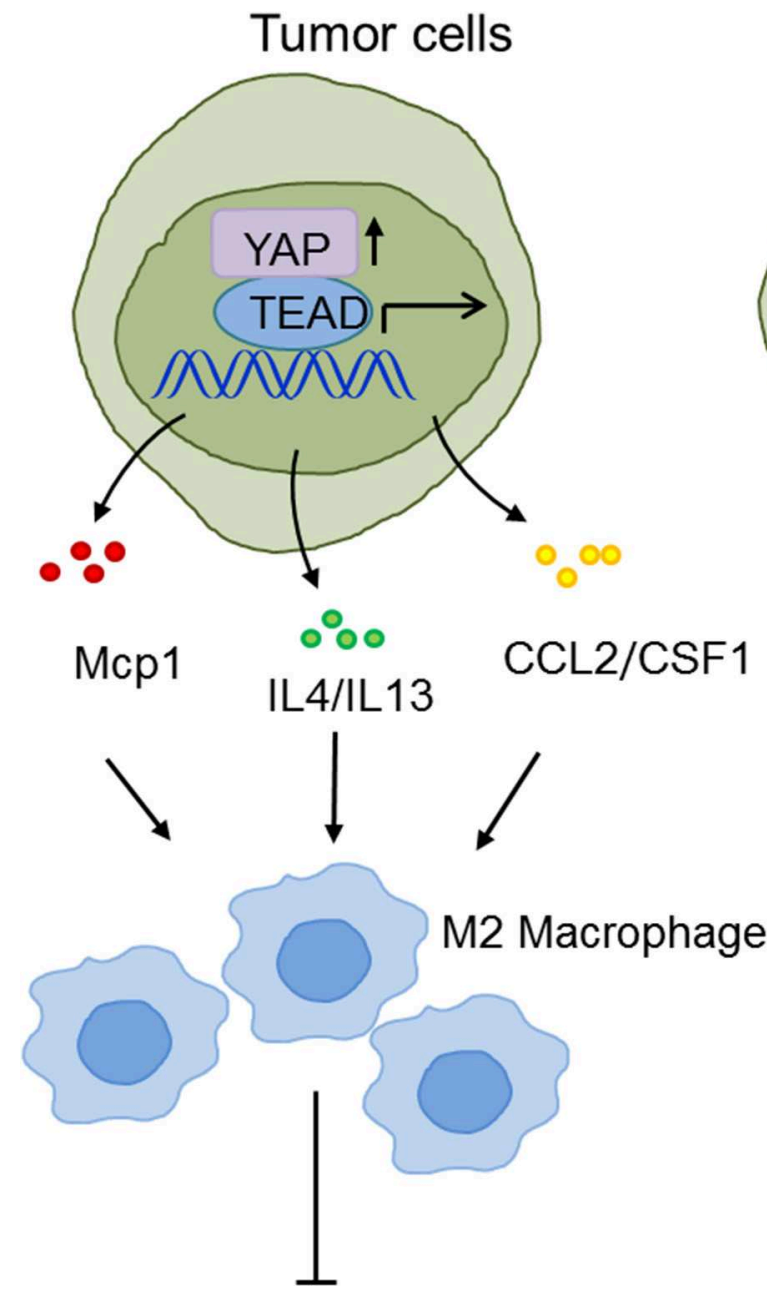

Anti-tumor immune
response
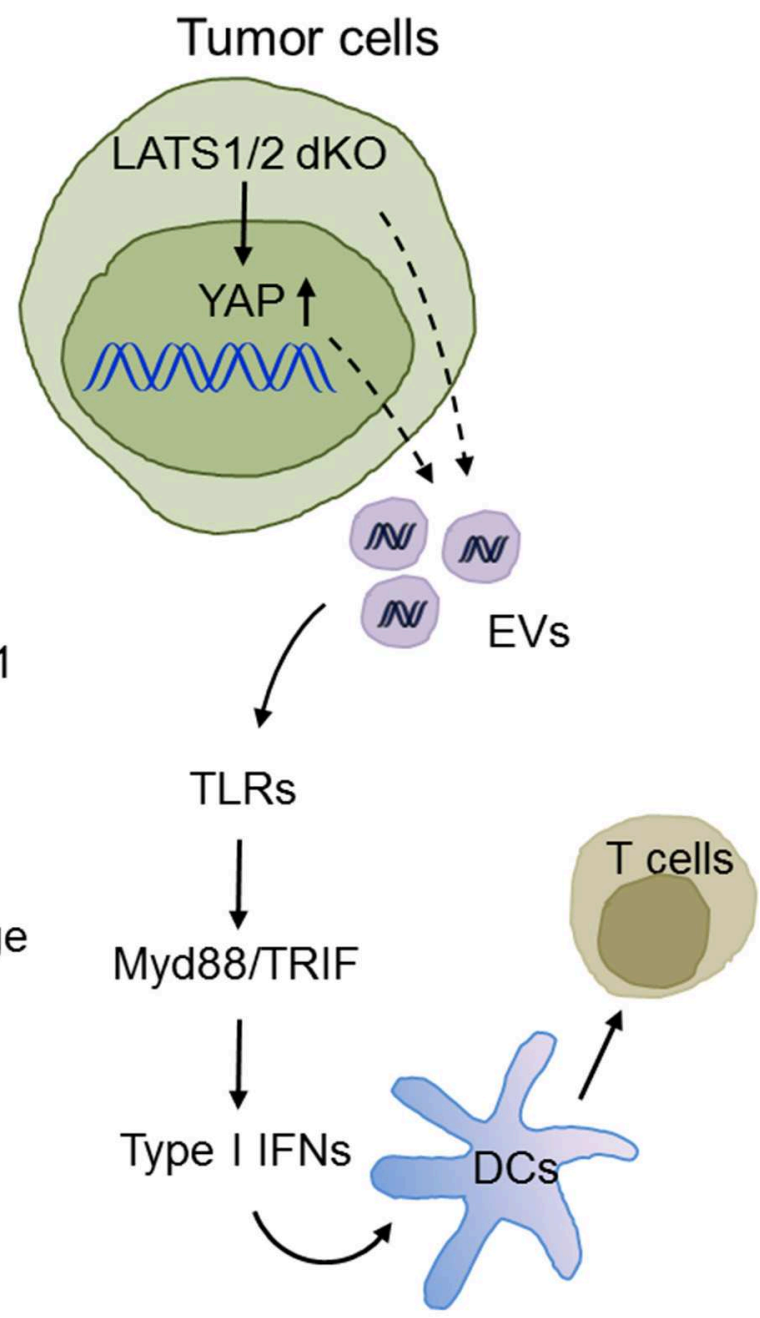

Anti-tumor immune
response

FIGURE 4 | The emerging roles of Hippo-YAP signaling in the modulation of innate anti-tumor immunity. The Hippo pathway maneuvers anti-tumor immune responses and tumorigenesis via regulating the production of type I IFNs and the infiltration, polarization, and maturation of innate immune cells.

inhibitors of TBK1, being directly associated with TBK1 and preventing the K63-linked ubiquitination and activation of TBK1 (41). In contrast, cellular conditions favoring YAP/TAZ inactivation and degradation relieved this YAP/TAZ-mediated TBK1 suppression and thus augmented the antiviral immunity (41). Zhou and colleagues also showed a few months later that YAP in macrophages negatively regulated the antiviral response via interfering with IRF3 dimerization and nuclear translocation (85). Other groups also revealed that YAP/TAZ attenuated NF- $\kappa \mathrm{B}$ signaling by directly inhibiting IKK $\alpha / \beta$ activation in an osteoarthritis murine model (88) and by associating with TRAF6 and facilitating TRAF6 degradation in vascular inflammation (90). Recently, the Yu group reported that an isoform of TAZ impeded JAK-STAT signaling to dampen the type I IFNs pathway (86). In addition, our group found that, independent of LATS kinases and YAP/TAZ, MST1 directly associated with and phosphorylated IRF3 to attenuate its dimerization and promoter binding (109), and our and other groups further revealed that MST1 was also suppressive of TBK1 activation (109, 110). During HIV-1 infection, the CLRs DC-SIGN recognized the abortive HIV-1 RNA and triggered Raf-1-dependent MST1 activation, which facilitated the phosphorylation and activation of mitotic kinase PLK1 to restrain TBK1 and thus compromise MAVS antiviral signaling (110). Given the overall deficiency of YAP/TAZ expression in many types of immune cells, the observations with regard to the similarity but not the distinction of YAP/TAZ and MST1 in innate immunity are rather intriguing. Taken together, these observations suggest a considerable involvement of the Hippo pathway in innate antiviral immunity and the negative effects of YAP/TAZ and MST1 in antiviral 
immunity, depending on the distinct physiological contexts (Figure 3).

\section{EMERGING ROLES OF HIPPO-YAP SIGNALING IN MODULATION OF INNATE ANTI-TUMOR IMMUNITY}

Type I IFNs bridge innate immunity and adaptive immunity and play a pivotal role in anti-tumor immunity (111-113). Given that there are numerous lines of evidence for the participation of the Hippo pathway in innate immunity, it is no surprise that Hippo-YAP signaling also effects anti-tumor immunity. For example, the Guan group suggested an unexpected function of the Hippo pathway in suppression of anti-tumor immunity in three murine models. Tumor cells with LATS1/2 deficiency secreted nucleic acid-rich EVs to facilitate TLRs-Myd88/TRIF signaling and type I IFN production, which accelerated DC maturation, $\mathrm{CD}^{+} \mathrm{T}$ lymphocyte expansion, and tumor growth arrest (93). In contrast, the Zhao group found that in liver tumor-initiating cells (TICs), YAP recruited M2 macrophages to suppress immune clearance, thus promoting tumorigenesis (63). In human HCC, the Yang group also reported that YAP activation induced the polarization of M1/M2 macrophages via Mcp1, thus contributing to massive macrophage infiltration and HCC progression (64). The Dey group reported that hyperactivated TAZ, but not YAP, accelerated liver inflammation and tumor development in a TEAD-dependent manner to induce myeloid cell infiltration and pro-inflammatory cytokine secretion (114). These somewhat diverse observations may reflect the fact that the complex tumor microenvironment and cancer cell types precisely determine the exact role of the Hippo-YAP signaling pathways in innate anti-tumor immunity. Future investigations are warranted to define these elaborate situations (Figure 4).

\section{CONCLUDING REMARKS}

Contrary to the classic functions of Hippo-YAP signaling in cell fate determination, tissue homeostasis, and organ development, accumulating data in recent years has clearly pointed to the critical roles of the Hippo-YAP pathway in innate immune

\section{REFERENCES}

1. Harvey KF, Pfleger CM, Hariharan IK. The drosophila Mst ortholog, Hippo, restricts growth and cell proliferation and promotes apoptosis. Cell. (2003) 114:457-67. doi: 10.1016/S0092-8674(03) 00557-9

2. Wu S, Huang J, Dong J, Pan D. hippo Encodes a Ste-20 family protein kinase that restricts cell proliferation and promotes apoptosis in conjunction with salvador and warts. Cell. (2003) 114:445-56. doi: 10.1016/S0092-8674(03)00549-X

3. Pantalacci S, Tapon N, Leopold P. The salvador partner Hippo promotes apoptosis and cell-cycle exit in drosophila. Nat Cell Biol. (2003) 5:9217. doi: $10.1038 /$ ncb1051

4. Udan RS, Kango-Singh M, Nolo R, Tao C, Halder G. Hippo promotes proliferation arrest and apoptosis in the salvador/warts pathway. Nat Cell Biol. (2003) 5:914-20. doi: 10.1038/ncb1050 regulation. In this review, we have summarized the intriguing but complex integrations of Hippo-YAP signaling in the functioning of innate immune cells and signaling with specific focuses on the innate anti-microbial immunity and anti-tumor immunity. An intrinsic part of the nature of the Hippo pathway is its very complicated interactions with innate immune signaling at multiple levels and independent or dependent of signaling effectors YAP/TAZ. The entirely distinct programs for the expression of these core signaling players in innate immune cells, particularly YAP and TAZ, appear to justify this requirement.

In conclusion, Hippo signaling through the kinase cascade to YAP/TAZ is a conceptually straightforward pathway. However, we have observed the amazing versatility and contextdependence of the Hippo pathway responses in innate immunity. Moving forward, we believe that systematic investigations under physiological settings are particularly needed to decipher the diversified functions and mechanisms of the Hippo pathway, which, ultimately, will guide us to maneuver this critical pathway to benefit our health.

\section{AUTHOR CONTRIBUTIONS}

QZ and PX reviewed the literature and wrote the manuscript. RZ contributed with data analyses and discussions. All authors contributed to the article and approved the submitted version.

\section{FUNDING}

The research described in the authors' laboratories was partly supported by grants of the NSFC Distinguished Young Scholars Program (31725017 to PX), the NSFC Projects (31830052 to PX and 81902915 to QZ), and the Initiative Postdocs Supporting Program (BX20180270 to QZ).

\section{ACKNOWLEDGMENTS}

In reviewing recent advances, we had to limit ourselves to only some observations illustrating the roles of Hippo-YAP signaling in innate immunity. Inevitably, many highly relevant findings could not be included. We therefore apologize to those researchers whose work was not included in this review.

5. Justice RW, Zilian O, Woods DF, Noll M, Bryant PJ. The drosophila tumor suppressor gene warts encodes a homolog of human myotonic dystrophy kinase and is required for the control of cell shape and proliferation. Genes Dev. (1995) 9:534-46. doi: 10.1101/gad.9.5.534

6. Kango-Singh M, Nolo R, Tao C, Verstreken P, Hiesinger PR, Bellen HJ, et al. Shar-pei mediates cell proliferation arrest during imaginal disc growth in drosophila. Development. (2002) 129:5719-30. doi: 10.1242/dev.00168

7. Huang J, Wu S, Barrera J, Matthews K, Pan D. The Hippo signaling pathway coordinately regulates cell proliferation and apoptosis by inactivating yorkie, the drosophila homolog of YAP. Cell. (2005) 122:421-34. doi: 10.1016/j.cell.2005.06.007

8. Lai ZC, Wei X, Shimizu T, Ramos E, Rohrbaugh M, Nikolaidis N, et al. Control of cell proliferation and apoptosis by mob as tumor suppressor, mats. Cell. (2005) 120:675-85. doi: 10.1016/j.cell.2004.12.036

9. Aragona M, Panciera T, Manfrin A, Giulitti S, Michielin F, Elvassore $\mathrm{N}$, et al. A mechanical checkpoint controls multicellular growth through 
YAP/TAZ regulation by actin-processing factors. Cell. (2013) 154:104759. doi: 10.1016/j.cell.2013.07.042

10. Meng Z, Qiu Y, Lin KC, Kumar A, Placone JK, Fang C, et al. RAP2 mediates mechanoresponses of the Hippo pathway. Nature. (2018) 560:65560. doi: 10.1038/s41586-018-0444-0

11. Yu FX, Zhao B, Panupinthu N, Jewell JL, Lian I, Wang LH, et al. Regulation of the Hippo-YAP pathway by G-protein-coupled receptor signaling. Cell. (2012) 150:780-91. doi: 10.1016/j.cell.2012.06.037

12. Yin F, Yu JZ, Zheng YG, Chen Q, Zhang NL, Pan DJ. Spatial organization of Hippo signaling at the plasma membrane mediated by the tumor suppressor merlin/NF2. Cell. (2013) 154:1342-55. doi: 10.1016/j.cell.2013.08.025

13. Meng ZP, Moroishi T, Mottier-Pavie V, Plouffe SW, Hansen CG, Hong AW, et al. MAP4K family kinases act in parallel to MST1/2 to activate LATS1/2 in the Hippo pathway. Nat Commun. (2015) 6:8357. doi: 10.1038/ncomms 9357

14. Zheng YG, Wang W, Liu B, Deng H, Uster E, Pan DJ. Identification of happyhour/MAP4K as alternative Hpo/Mst-like kinases in the Hippo kinase cascade. Dev Cell. (2015) 34:642-55. doi: 10.1016/j.devcel.2015.08.014

15. Boggiano JC, Vanderzalm PJ, Fehon RG. Tao-1 phosphorylates hippo/MST kinases to regulate the Hippo-salvador-warts tumor suppressor pathway. Dev Cell. (2011) 21:888-95. doi: 10.1016/j.devcel.2011.08.028

16. Poon CLC, Lin JI, Zhang XM, Harvey KF. The sterile 20-like kinase Tao-1 controls tissue growth by regulating the salvador-warts-Hippo pathway. Dev Cell. (2011) 21:896-906. doi: 10.1016/j.devcel.2011.09.012

17. Mo JS, Meng ZP, Kim YC, Park HW, Hansen CG, Kim S, et al. Cellular energy stress induces AMPK-mediated regulation of YAP and the Hippo pathway. Nat Cell Biol. (2015) 17:500-10. doi: 10.1038/ncb3111

18. Wang W, Xiao ZD, Li X, Aziz KE, Gan B, Johnson RL, et al. AMPK modulates Hippo pathway activity to regulate energy homeostasis. Nat Cell Biol. (2015) 17:490-99. doi: 10.1038/ncb3113

19. Dupont S, Morsut L, Aragona M, Enzo E, Giulitti S, Cordenonsi M, et al. Role of YAP/TAZ in mechanotransduction. Nature. (2011) 474:17983. doi: $10.1038 /$ nature 10137

20. Zhao B, Li L, Tumaneng K, Wang CY, Guan KL. A coordinated phosphorylation by lats and CK1 regulates YAP stability through SCF(betaTRCP). Genes Dev. (2010) 24:72-85. doi: 10.1101/gad.1843810

21. Zhao B, Wei X, Li W, Udan RS, Yang Q, Kim J, et al. Inactivation of YAP oncoprotein by the Hippo pathway is involved in cell contact inhibition and tissue growth control. Genes Dev. (2007) 21:274761. doi: 10.1101/gad.1602907

22. Dong J, Feldmann G, Huang J, Wu S, Zhang N, Comerford SA, et al. Elucidation of a universal size-control mechanism in drosophila and mammals. Cell. (2007) 130:1120-33. doi: 10.1016/j.cell.2007.07.019

23. Pan D. The hippo signaling pathway in development and cancer. Dev Cell. (2010) 19:491-505. doi: 10.1016/j.devcel.2010.09.011

24. Zhao B, Li L, Lei Q, Guan KL. The Hippo-YAP pathway in organ size control and tumorigenesis: an updated version. Genes Dev. (2010) 24:86274. doi: 10.1101/gad.1909210

25. Cao X, Pfaff SL, Gage FH. YAP regulates neural progenitor cell number via the TEA domain transcription factor. Genes Dev. (2008) 22:332034. doi: $10.1101 /$ gad. 1726608

26. Zhao B, Ye X, Yu J, Li L, Li W, Li S, et al. TEAD mediates YAPdependent gene induction and growth control. Genes Dev. (2008) 22:196271. doi: $10.1101 /$ gad. 1664408

27. Ma S, Meng Z, Chen R, Guan KL. The hippo pathway: biology and pathophysiology. Annu Rev Biochem. (2018) 88:577-604. doi: 10.1146/annurev-biochem-013118-111829

28. Halder G, Johnson RL. Hippo signaling: growth control and beyond. Development. (2011) 138:9-22. doi: 10.1242/dev.045500

29. Schlegelmilch K, Mohseni M, Kirak O, Pruszak J, Rodriguez JR, Zhou D, et al. Yap1 acts downstream of alpha-catenin to control epidermal proliferation. Cell. (2011) 144:782-95. doi: 10.1016/j.cell.2011.02.031

30. Reginensi A, Scott RP, Gregorieff A, Bagherie-Lachidan M, Chung C, Lim DS, et al. Yap- and Cdc42-dependent nephrogenesis and morphogenesis during mouse kidney development. PLoS Genet. (2013) 9:e1003380. doi: 10.1371/journal.pgen.1003380

31. von Gise A, Lin Z, Schlegelmilch K, Honor LB, Pan GM, Buck JN, et al. YAP1 the nuclear target of Hippo signaling, stimulates heart growth through cardiomyocyte proliferation but not hypertrophy. Proc Natl Acad Sci USA. (2012) 109:2394-9. doi: 10.1073/pnas.1116136109

32. Xin M, Kim Y, Sutherland LB, Qi X, McAnally J, Schwartz RJ, et al. Regulation of insulin-like growth factor signaling by Yap governs cardiomyocyte proliferation and embryonic heart size. Sci Signal. (2011) 4:ra70. doi: 10.1126/scisignal.2002278

33. Barry ER, Morikawa T, Butler BL, Shrestha K, de la Rosa R, Yan KS, et al. Restriction of intestinal stem cell expansion and the regenerative response by YAP. Nature. (2013) 493:106-10. doi: 10.1038/nature11693

34. Cordenonsi M, Zanconato F, Azzolin L, Forcato M, Rosato A, Frasson C, et al. The Hippo transducer TAZ confers cancer stem cell-related traits on breast cancer cells. Cell. (2011) 147:759-72. doi: 10.1016/j.cell.2011.09.048

35. Fernandez LA, Squatrito M, Northcott P, Awan A, Holland EC, Taylor MD, et al. Oncogenic YAP promotes radioresistance and genomic instability in medulloblastoma through IGF2-mediated Akt activation. Oncogene. (2012) 31:1923-37. doi: 10.1038/onc.2011.379

36. Fu V, Plouffe SW, Guan KL. The Hippo pathway in organ development, homeostasis, and regeneration. Curr Opin Cell Biol. (2017) 49:99107. doi: $10.1016 /$ j.ceb.2017.12.012

37. Camargo FD, Gokhale S, Johnnidis JB, Fu D, Bell GW, Jaenisch R, et al. YAP1 increases organ size and expands undifferentiated progenitor cells. Curr Biol. (2007) 17:2054-60. doi: 10.1016/j.cub.2007.10.039

38. Varelas X, Sakuma R, Samavarchi-Tehrani P, Peerani R, Rao BM, Dembowy J, et al. TAZ controls Smad nucleocytoplasmic shuttling and regulates human embryonic stem-cell self-renewal. Nat Cell Biol. (2008) 10:83748. doi: $10.1038 / \mathrm{ncb} 1748$

39. Varelas X, Miller BW, Sopko R, Song S, Gregorieff A, Fellouse FA, et al. The Hippo pathway regulates Wnt/beta-catenin signaling. Dev Cell. (2010) 18:579-91. doi: 10.1016/j.devcel.2010.03.007

40. Mo JS, Yu FX, Gong R, Brown JH, Guan KL. Regulation of the HippoYAP pathway by protease-activated receptors (PARs). Genes Dev. (2012) 26:2138-43. doi: 10.1101/gad.197582.112

41. Zhang Q, Meng F, Chen S, Plouffe SW, Wu S, Liu S, et al. Hippo signalling governs cytosolic nucleic acid sensing through YAP/TAZ-mediated TBK1 blockade. Nat Cell Biol. (2017) 19:362-74. doi: 10.1038/ncb3496

42. Liu B, Zheng Y, Yin F, Yu J, Silverman N, Pan D. Toll receptor-mediated Hippo signaling controls innate immunity in drosophila. Cell. (2016) 164:406-19. doi: 10.1016/j.cell.2015.12.029

43. Codelia VA, Sun G, Irvine KD. Regulation of YAP by mechanical strain through Jnk and Hippo signaling. Curr Biol. (2014) 24:201217. doi: 10.1016/j.cub.2014.07.034

44. Poon CL, Zhang X, Lin JI, Manning SA, Harvey KF. Homeodomaininteracting protein kinase regulates Hippo pathway-dependent tissue growth. Curr Biol. (2012) 22:1587-94. doi: 10.1016/j.cub.2012.06.075

45. Levy D, Adamovich Y, Reuven N, Shaul Y. Yap1 phosphorylation by c-Abl is a critical step in selective activation of proapoptotic genes in response to DNA damage. Mol Cell. (2008) 29:350-61. doi: 10.1016/j.molcel.2007.12.022

46. Zaidi SK, Sullivan AJ, Medina R, Ito Y, van Wijnen AJ, Stein JL, et al. Tyrosine phosphorylation controls Runx2-mediated subnuclear targeting of YAP to repress transcription. EMBO J. (2004) 23:7909. doi: $10.1038 /$ sj.emboj.7600073

47. Jang EJ, Jeong H, Han KH, Kwon HM, Hong JH, Hwang ES. TAZ suppresses NFAT5 activity through tyrosine phosphorylation. Mol Cell Biol. (2012) 32:4925-32. doi: 10.1128/MCB.00392-12

48. Li P, Silvis MR, Honaker Y, Lien WH, Arron ST, Vasioukhin V. $\alpha$ Ecatenin inhibits a Src-YAP1 oncogenic module that couples tyrosine kinases and the effector of Hippo signaling pathway. Genes Dev. (2016) 30:798811. doi: $10.1101 /$ gad.274951.115

49. Kim NG, Gumbiner BM. Adhesion to fibronectin regulates Hippo signaling via the FAK-Src-PI3K pathway. J Cell Biol. (2015) 210:50315. doi: $10.1083 /$ jcb. 201501025

50. Yu FX, Zhao B, Guan KL. Hippo pathway in organ size control, tissue homeostasis, and cancer. Cell. (2015) 163:81128. doi: 10.1016/j.cell.2015.10.044

51. Du X, Wen J, Wang Y, Karmaus PWF, Khatamian A, Tan H, et al. Hippo/Mst signalling couples metabolic state and immune function of $\mathrm{CD} 8 \alpha^{+}$dendritic cells. Nature. (2018) 558:141-5. doi: 10.1038/s41586-018-0177-0 
52. Zhao L, Guan H, Song C, Wang Y, Liu C, Cai C, et al. YAP1 is essential for osteoclastogenesis through a TEADs-dependent mechanism. Bone. (2018) 110:177-86. doi: 10.1016/j.bone.2018.01.035

53. Zhang YL, Li Q, Yang XM, Fang F, Li J, Wang YH, et al. SPON2 promotes M1-like macrophage recruitment and inhibits hepatocellular carcinoma metastasis by distinct integrin-Rho GTPase-Hippo pathways. Cancer Res. (2018) 78:2305-17. doi: 10.1158/0008-5472.CAN-17-2867

54. Katagiri K, Katakai T, Ebisuno Y, Ueda Y, Okada T, Kinashi T. Mst1 controls lymphocyte trafficking and interstitial motility within lymph nodes. EMBO J. (2009) 28:1319-31. doi: 10.1038/emboj.2009.82

55. Torres-Bacete J, Delgado-Martin C, Gomez-Moreira C, Simizu S, RodriguezFernandez JL. The mammalian sterile 20-like 1 kinase controls selective CCR7-dependent functions in human dendritic cells. J Immunol. (2015) 195:973-81. doi: 10.4049/jimmunol.1401966

56. Huang YJ, Yang CK, Wei PL, Huynh TT, Whang-Peng J, Meng TC, et al. Ovatodiolide suppresses colon tumorigenesis and prevents polarization of M2 tumor-associated macrophages through YAP oncogenic pathways. $J$ Hematol Oncol. (2017) 10:60. doi: 10.1186/s13045-017-0421-3

57. Locati M, Mantovani A, Sica A. Macrophage activation and polarization as an adaptive component of innate immunity. Adv Immunol. (2013) 120:16384. doi: 10.1016/B978-0-12-417028-5.00006-5

58. Kelly B, O'Neill LA. Metabolic reprogramming in macrophages and dendritic cells in innate immunity. Cell Res. (2015) 25:771-84. doi: 10.1038/cr.2015.68

59. McGaha TL, Chen Y, Ravishankar B, van Rooijen N, Karlsson MC. Marginal zone macrophages suppress innate and adaptive immunity to apoptotic cells in the spleen. Blood. (2011) 117:5403-12. doi: 10.1182/blood-2010-11-320028

60. Biswas SK, Mantovani A. Macrophage plasticity and interaction with lymphocyte subsets: cancer as a paradigm. Nat Immunol. (2010) 11:88996. doi: 10.1038/ni.1937

61. Noy R, Pollard JW. Tumor-associated macrophages: from mechanisms to therapy. Immunity. (2014) 41:49-61. doi: 10.1016/j.immuni.2014.06.010

62. Thaventhiran JE, Hoffmann A, Magiera L, de la Roche M, Lingel H, BrunnerWeinzierl M, et al. Activation of the Hippo pathway by CTLA-4 regulates the expression of Blimp-1 in the CD8+ T cell. Proc Natl Acad Sci USA. (2012) 109:E2223-9. doi: 10.1073/pnas.1209115109

63. Guo X, Zhao Y, Yan H, Yang Y, Shen S, Dai X, et al. Single tumor-initiating cells evade immune clearance by recruiting type II macrophages. Genes Dev. (2017) 31:247-59. doi: 10.1101/gad.294348.116

64. Kim W, Khan SK, Liu Y, Xu R, Park O, He Y, et al. Hepatic Hippo signaling inhibits protumoural microenvironment to suppress hepatocellular carcinoma. Gut. (2018) 67:1692-703. doi: 10.1136/gutjnl-2017-314061

65. Zhou X, Li W, Wang S, Zhang $\mathrm{P}$, Wang Q, Xiao J, et al. YAP aggravates inflammatory bowel disease by regulating M1/M2 macrophage polarization and gut microbial homeostasis. Cell Rep. (2019) 27:117689.e1175. doi: 10.1016/j.celrep.2019.03.028

66. Mooring M, Fowl BH, Lum SZC, Liu Y, Yao K, Softic S, et al. Hepatocyte stress increases expression of yes-associated protein and transcriptional coactivator with PDZ-binding motif in hepatocytes to promote parenchymal inflammation and fibrosis. Hepatology. (2019) 71:1813-30. doi: 10.1002/hep.30928

67. Murphy TL, Grajales-Reyes GE, Wu X, Tussiwand R, Briseno CG, Iwata A, et al. Transcriptional control of dendritic cell development. Annu Rev Immunol. (2016) 34:93-119. doi: 10.1146/annurev-immunol-032713-120204

68. Merad M, Sathe P, Helft J, Miller J, Mortha A. The dendritic cell lineage: ontogeny and function of dendritic cells and their subsets in the steady state and the inflamed setting. Annu Rev Immunol. (2013) 31:563604. doi: 10.1146/annurev-immunol-020711-074950

69. Dudziak D, Kamphorst AO, Heidkamp GF, Buchholz VR, Trumpfheller C, Yamazaki S, et al. Differential antigen processing by dendritic cell subsets in vivo. Science. (2007) 315:107-11. doi: 10.1126/science. 1136080

70. Kawai T, Akira S. Toll-like receptors and their crosstalk with other innate receptors in infection and immunity. Immunity. (2011) 34:63750. doi: 10.1016/j.immuni.2011.05.006

71. Takeuchi O, Akira S. Pattern recognition receptors and inflammation. Cell. (2010) 140:805-20. doi: 10.1016/j.cell.2010.01.022
72. Dambuza IM, Brown GD. C-type lectins in immunity: recent developments Curr Opin Immunol. (2015) 32:21-27. doi: 10.1016/j.coi.2014.12.002

73. Yoneyama M, Kikuchi M, Natsukawa T, Shinobu N, Imaizumi T, Miyagishi $\mathrm{M}$, et al. The RNA helicase RIG-I has an essential function in doublestranded RNA-induced innate antiviral responses. Nat Immunol. (2004) 5:730-7. doi: 10.1038/ni1087

74. Hornung V, Ellegast J, Kim S, Brzozka K, Jung A, Kato H, et al. 5'Triphosphate RNA is the ligand for RIG-I. Science. (2006) 314:9947. doi: 10.1126/science.1132505

75. Pichlmair A, Schulz O, Tan CP, Naslund TI, Liljestrom P, Weber F, et al. RIG-I-mediated antiviral responses to single-stranded RNA bearing 5'phosphates. Science. (2006) 314:997-1001. doi: 10.1126/science.1132998

76. Kato H, Takeuchi O, Sato S, Yoneyama M, Yamamoto M, Matsui K, et al. Differential roles of MDA5 and RIG-I helicases in the recognition of RNA viruses. Nature. (2006) 441:101-5. doi: 10.1038/nature04734

77. Civril F, Deimling T, de Oliveira Mann CC, Ablasser A, Moldt M, Witte G, et al. Structural mechanism of cytosolic DNA sensing by cGAS. Nature. (2013) 498:332-7. doi: 10.1038/nature12305

78. Gao P, Ascano M, Wu Y, Barchet W, Gaffney BL, Zillinger T, et al. Cyclic $\left[\mathrm{G}\left(2^{\prime}, 5^{\prime}\right) \mathrm{pA}\left(3^{\prime}, 5^{\prime}\right) \mathrm{p}\right]$ is the metazoan second messenger produced by DNA-activated cyclic GMP-AMP synthase. Cell. (2013) 153:1094107. doi: 10.1016/j.cell.2013.04.046

79. Li XD, Wu J, Gao D, Wang H, Sun L, Chen ZJ. Pivotal roles of cGAS-cGAMP signaling in antiviral defense and immune adjuvant effects. Science. (2013) 341:1390-4. doi: 10.1126/science. 1244040

80. Sun L, Wu J, Du F, Chen X, Chen ZJ. Cyclic GMP-AMP synthase is a cytosolic DNA sensor that activates the type I interferon pathway. Science. (2013) 339:786-91. doi: 10.1126/science.1232458

81. Inohara N, Koseki T, del Peso L, Hu Y, Yee C, Chen S, et al. Nod1, an Apaf1-like activator of caspase-9 and nuclear factor-kappaB. J Biol Chem. (1999) 274:14560-7. doi: 10.1074/jbc.274.21.14560

82. Ogura Y, Inohara N, Benito A, Chen FF, Yamaoka S, Nunez G. Nod2, a Nod1/Apaf-1 family member that is restricted to monocytes and activates NF-kappaB. J Biol Chem. (2001) 276:4812-18. doi: 10.1074/jbc.M008072200

83. Goubau D, Deddouche S, Reis e Sousa C. Cytosolic sensing of viruses. Immunity. (2013) 38:855-69, doi: 10.1016/j.immuni.2013.05.007

84. Rathinam VA, Vanaja SK, Fitzgerald KA. Regulation of inflammasome signaling. Nat Immunol. (2012) 13:333-42. doi: 10.1038/ni.2237

85. Wang S, Xie F, Chu F, Zhang Z, Yang B, Dai T, et al. YAP antagonizes innate antiviral immunity and is targeted for lysosomal degradation through IKKvarepsilon-mediated phosphorylation. Nat Immunol. (2017) 18:73343. doi: 10.1038/ni.3744

86. Fang C, Li J, Qi S, Lei Y, Zeng Y, Yu P, et al. An alternatively transcribed TAZ variant negatively regulates JAK-STAT signaling. EMBO Rep. (2019) 20:e47227. doi: 10.15252/embr.201847227

87. Ni X, Tao J, Barbi J, Chen Q, Park BV, Li Z, et al. YAP is essential for treg-mediated suppression of antitumor immunity. Cancer Discov. (2018) 8:1026-43. doi: 10.1158/2159-8290.CD-17-1124

88. Deng Y, Lu J, Li W, Wu A, Zhang X, Tong W, et al. Reciprocal inhibition of YAP/TAZ and NF-kappaB regulates osteoarthritic cartilage degradation. Nat Commun. (2018) 9:4564. doi: 10.1038/s41467-018-07022-2

89. Huang Z, Wang Y, Hu G, Zhou J, Mei L, Xiong WC. YAP is a critical inducer of SOCS3, preventing reactive astrogliosis. Cereb Cortex. (2016) 26:2299-310. doi: 10.1093/cercor/bhv292

90. Lv Y, Kim K, Sheng Y, Cho J, Qian Z, Zhao YY, et al. YAP controls endothelial activation and vascular inflammation through TRAF6. Circ Res. (2018) 123:43-56. doi: 10.1161/CIRCRESAHA.118.313143

91. Ramjee V, Li D, Manderfield LJ, Liu F, Engleka KA, Aghajanian $\mathrm{H}$, et al. Epicardial YAP/TAZ orchestrate an immunosuppressive response following myocardial infarction. J Clin Invest. (2017) 127:899-911. doi: 10.1172/JCI88759

92. Li C, Jin Y, Wei S, Sun Y, Jiang L, Zhu Q, et al. Hippo signaling controls NLR family pyrin domain containing 3 activation and governs immunoregulation of mesenchymal stem cells in mouse liver injury. Hepatology. (2019) 70:1714-31. doi: 10.1002/hep.30700

93. Moroishi T, Hayashi T, Pan WW, Fujita Y, Holt MV, Qin J, et al. The Hippo pathway kinases LATS1/2 suppress cancer immunity. Cell. (2016) 167:1525-39.e1517. doi: 10.1016/j.cell.2016.11.005 
94. Ye S, Lawlor MA, Rivera-Reyes A, Egolf S, Chor S, Pak K, et al. YAP1-mediated suppression of USP31 enhances NFkappaB activity to promote sarcomagenesis. Cancer Res. (2018) 78:270520. doi: 10.1158/0008-5472.CAN-17-4052

95. Wang L, Luo JY, Li B, Tian XY, Chen LJ, Huang Y, et al. Integrin-YAP/TAZJNK cascade mediates atheroprotective effect of unidirectional shear flow. Nature. (2016) 540:579-82. doi: 10.1038/nature20602

96. Houtz P, Bonfini A, Liu X, Revah J, Guillou A, Poidevin M, et al. TGFbeta, and Src-MAPK pathways regulate transcription of the upd3 cytokine in drosophila enterocytes upon bacterial infection. PLoS Genet. (2017) 13:e1007091. doi: 10.1371/journal.pgen.1007091

97. Lee PC, Machner MP. The legionella effector kinase LegK7 hijacks the host Hippo pathway to promote infection. Cell Host Microbe. (2018) 24:42938.e426. doi: 10.1016/j.chom.2018.08.004

98. Geng J, Sun X, Wang P, Zhang S, Wang X, Wu H, et al. Kinases Mst1 and Mst2 positively regulate phagocytic induction of reactive oxygen species and bactericidal activity. Nat Immunol. (2015) 16:1142-52. doi: 10.1038/ni.3268

99. West AP, Brodsky IE, Rahner C, Woo DK, Erdjument-Bromage H, Tempst $\mathrm{P}$, et al. TLR signalling augments macrophage bactericidal activity through mitochondrial ROS. Nature. (2011) 472:476-80. doi: 10.1038/nature09973

100. Li W, Xiao J, Zhou X, Xu M, Hu C, Xu X, et al. STK4 regulates TLR pathways and protects against chronic inflammation-related hepatocellular carcinoma. J Clin Invest. (2015) 125:4239-54. doi: 10.1172/JCI81203

101. Jiao S, Zhang Z, Li C, Huang M, Shi Z, Wang Y, et al. The kinase MST4 limits inflammatory responses through direct phosphorylation of the adaptor TRAF6. Nat Immunol. (2015) 16:246-57. doi: 10.1038/ni.3097

102. Kawai T, Takahashi K, Sato S, Coban C, Kumar H, Kato H, et al. IPS-1, an adaptor triggering RIG-I- and Mda5-mediated type I interferon induction. Nat Immunol. (2005) 6:981-8. doi: 10.1038/ni1243

103. Seth RB, Sun L, Ea CK, Chen ZJ. Identification and characterization of MAVS, a mitochondrial antiviral signaling protein that activates NF-kappaB and IRF 3. Cell. (2005) 122:669-82. doi: 10.1016/j.cell.2005.08.012

104. Xu LG, Wang YY, Han KJ, Li LY, Zhai Z, Shu HB. VISA is an adapter protein required for virus-triggered IFN-beta signaling. Mol Cell. (2005) 19:727-40. doi: 10.1016/j.molcel.2005.08.014

105. Ishikawa H, Barber GN. STING is an endoplasmic reticulum adaptor that facilitates innate immune signalling. Nature. (2008) 455:674-8. doi: 10.1038/nature07317
106. Zhong B, Yang Y, Li S, Wang YY, Li Y, Diao F, et al. The adaptor protein MITA links virus-sensing receptors to IRF3 transcription factor activation. Immunity. (2008) 29:538-50. doi: 10.1016/j.immuni.2008.09.003

107. Fitzgerald KA, McWhirter SM, Faia KL, Rowe DC, Latz E, Golenbock DT, et al. IKKepsilon and TBK1 are essential components of the IRF3 signaling pathway. Nat Immunol. (2003) 4:491-6. doi: 10.1038/ni921

108. Sharma S, tenOever BR, Grandvaux N, Zhou GP, Lin R, Hiscott J. Triggering the interferon antiviral response through an IKK-related pathway. Science. (2003) 300:1148-51. doi: 10.1126/science.1081315

109. Meng F, Zhou R, Wu S, Zhang Q, Jin Q, Zhou Y, et al. Mst1 shuts off cytosolic antiviral defense through IRF3 phosphorylation. Genes Dev. (2016) 30:1086-100. doi: 10.1101/gad.277533.116

110. Gringhuis SI, Hertoghs N, Kaptein TM, Zijlstra-Willems EM, SarramiForooshani R, Sprokholt JK, et al. HIV-1 blocks the signaling adaptor MAVS to evade antiviral host defense after sensing of abortive HIV-1 RNA by the host helicase DDX3. Nat Immunol. (2017) 18:225-35. doi: 10.1038/ni.3647

111. Fuertes MB, Woo SR, Burnett B, Fu YX, Gajewski TF. Type I interferon response and innate immune sensing of cancer. Trends Immunol. (2013) 34:67-73. doi: 10.1016/j.it.2012.10.004

112. Mantovani A, Allavena P, Sica A, Balkwill F. Cancer-related inflammation. Nature. (2008) 454:436-44. doi: 10.1038/nature07205

113. Grivennikov SI, Greten FR, Karin M. Immunity, inflammation, and cancer. Cell. (2010) 140:883-99. doi: 10.1016/j.cell.2010.01.025

114. Hagenbeek TJ, Webster JD, Kljavin NM, Chang MT, Pham T, Lee HJ, et al. The Hippo pathway effector TAZ induces TEADdependent liver inflammation and tumors. Sci Signal. (2018) 11:eaaj1757. doi: 10.1126/scisignal.aaj1757

Conflict of Interest: The authors declare that the research was conducted in the absence of any commercial or financial relationships that could be construed as a potential conflict of interest.

Copyright (c) 2020 Zhang, Zhou and Xu. This is an open-access article distributed under the terms of the Creative Commons Attribution License (CC BY). The use, distribution or reproduction in other forums is permitted, provided the original author(s) and the copyright owner(s) are credited and that the original publication in this journal is cited, in accordance with accepted academic practice. No use, distribution or reproduction is permitted which does not comply with these terms. 